\title{
ANALISIS SIFAT MEKANIS KOMPOSIT POLYESTER YANG DIPERKUAT SERAT KULIT DURIAN (DURIO ZIBETHINUS MURR) AKIBAT VARIASI FRAKSI VOLUME
}

\author{
Arthur Yanny Leiwakabessy ${ }^{1 *}$, Benjamin G. Tentua ${ }^{2}$, Fany Laamena ${ }^{3}$ \\ 1Jurusan Teknik Mesin Fakultas Teknik Universitas Pattimura, Ambon, 97233 \\ *Email: arthur.leiwakabessy@gmail.com \\ ${ }^{2}$ Jurusan Teknik Mesin Fakultas Teknik Universitas Pattimura, Ambon, 97233 \\ Email: benjamin.tentua@fatek.unpatti.ac.id \\ 3Jurusan Teknik Mesin Fakultas Teknik Universitas Pattimura, Ambon, 97233 \\ Email: laamenafany@gmail.com
}

\begin{abstract}
Abstrak. Komposit serat kulit buah durian sebagai penguat menjadi salah satu bidang penelitian yang menarik. Beberapa keuntungan yang terkait dengan penggunaan serat alami karena penguatan pada polimer adalah sifat non-abrasif dan konsumsi biaya rendah. Kulit buah durian bila diolah lebih lanjut dapat dibuat menjadi serat selulosa yang dapat dijadikan sebagai pengisi alami pada komposit polyester tidak jenuh. Di antara berbagai jenis serat alam, serat kulit durian merupakan salah satu alternatif filler komposit polymer. Kulit durian dapat diperoleh dengan mudah karena merupakan limbah keluarga yang belum dimanfaatkan. Untuk mendapatkan material komposit baru berbahan baku limbah kulit durian, serta dapat membantu masyarakat dan pemerintah dalam penanganan limbah kulit durian. Tujuan dari penelitian ini menentukan nilai maksimal variasi fraksi volume serat kulit durian terhadap nilai kekuatan impak dan kekuatan kekerasan sesuai aplikasi yang diinginkan. Penelitian ini menggunakan metode Hand Lay Up, dalam pembuatan komposit serat tunggal dengan variasi fraksi volume serat kulit durian : matrik polyester yaitu, 10\%:90\%, 20\%:80\%, 30\%:70\%, 40\%:60\% dan 50\%:50\%. Hasil penelitian adalah terjadi kenaikan kekuatan impak dan kekuatan kekerasan seiring penambahan fraksi volume, dimana energi impak tertinggi untuk fraksi volume serat kulit durian 50\%: 50\%, sebesar 0,7738 J, dan harga impak tertinggi sebesar $0,0096725 \mathrm{~J} / \mathrm{mm}^{2}$ dan energy impak terendah 10\%:90\%, sebesar 0,461 J.dan harga impak terendah sebesar $0,0057685 \mathrm{~J} / \mathrm{mm}^{2}$. Sehingga dapat disimpulkan bahwa kekuatan impak dan kekerasan komposit serat kulit durian mengalami peningkatan seiring dengan bertambahnya fraksi volume serat.
\end{abstract}

Kata kunci : Serat kulit durian, polyester, uji impak

\begin{abstract}
Durian rind fiber composite as a reinforcement is one of the interesting research areas. Some of the advantages associated with using natural fibers due to reinforcement in polymers are their non-abrasive properties and low-cost consumption. Durian rind when processed further can be made into cellulose fiber which can be used as a natural filler in unsaturated polyester composites. Among various types of natural fibers, durian skin fiber is an alternative polymer composite filler. Durian skin can be obtained easily because it is a family waste that has not been used. To get a new composite material made from durian skin waste, and to help the community and government in handling durian skin waste. The purpose of this study was to determine the maximum value of the variation of the volume fraction of durian skin fiber on the impact strength and hardness strength according to the desired application. This study uses the Hand Lay Up method, in the manufacture of single fiber composites with variations in volume fraction of durian skin fiber: polyester matrix, namely, 10\%: 90\%, 20\%: 80\%, 30\%: 70\%, 40\%: 60\% and 50\%:50\%. The results showed that there was an increase in the impact strength and hardness strength with the addition of the volume
\end{abstract}


fraction, where the highest impact energy for the volume fraction of durian skin fiber was 50\%: 50\%, $0.7738 \mathrm{~J}$, and the highest impact value was $0.0096725 \mathrm{~J} / \mathrm{mm}^{2}$ and energy the lowest impact is 10\%: 90\%, $0.461 \mathrm{~J}$. and the lowest impact price is $0.0057685 \mathrm{~J} / \mathrm{mm}^{2}$. So it can be concluded that the impact strength and hardness of the durian skin fiber composite increased with the increase in the volume fraction of the fiber.

Keywords: Durian peel fiber, polyester, impact test

\section{PENDAHULUAN}

Buah durian (Durio zibethinus Murr) termasuk buah musiman. Kulit buah durian bila diolah lebih lanjut dapat dibuat menjadi serat selulosa yang dapat dijadikan sebagai pengisi alami pada komposit polyester tidak jenuh [1]. Di antara berbagai jenis serat alam, serat kulit durian merupakan salah satu alternatif filler komposit polymer [2]. Kulit durian dapat diperoleh dengan mudah karena merupakan limbah keluarga yang belum dimanfaatkan. Selama ini, bagian buah durian yang lebih umum dikonsumsi adalah bagian dagingnya. Presentase berat bagian ini termasuk rendah yaitu hanya $20-35 \%$. Hal ini berarti kulit $(60-75 \%)$ dan biji $(5-15 \%)$ belum termanfaatkan secara maksimal (Wahyono, 2009)[3]. Alasan pemilihan serat kulit durian sebagai bahan baku komposit adalah karena merupakan hasil dari limbah buah durian, murah, mudah diperoleh dalam jumlah banyak, yang terdapat di provinsi Maluku.

Peneliti sebelumnya dialkukan untuk melihat Pengaruh penambahan serat kulit durian terhadap kuat tekan dan tarik belah pada mutu beton K-175 [4]. Tujuannya untuk mengetahui berapa besar pengurangan atau penambahan kuat tekan beton terhadap faktor keamanan suatu bagunan, untuk dapat diaplikasikan pada bangunan-bangunan masyarakat umum. Dalam penelitian ini, menggunakan beton yang merupakan campuran air, semen, agregat halus, agregat kasar, dan serat kulit durian. Dari hasil penelitian dapat ditarik kesimpulan bahwa, dari hasil uji kuat tekan beton dengan penambahan kulit durian $0,5 \%, 1,0 \%$ dan $1,5 \%$ mengalami peningkatan sebesar $2,71 \%$, $3,29 \%$, dan 4,97\% dibandingkan beton normal. Untuk hasil pengujian kuat tarik belah beton dengan penambahan kulit durian sebanyak $0,5 \%$, $1,0 \%$, dan $1,5 \%$ mengalami peningkatan sebesar $6,06 \%, 4,55 \%$, dan $3,03 \%$ dibanding beton normal [4].

Jenis pengikat yang digunakan dalam penelitian ini adalah resin polyester. Resin polyester merupakan salah satu resin termoset yang mudah diperoleh dan digunakan masyarakat umum maupun industri skala kecil maupun besar [5]. Resin polyester ini juga mempunyai kemampuan berikatan dengan serat alam tanpa menimbulkan reaksi dan gas, oleh karena itu resin polyester digunakan dalam penelitian ini adalah resin poliester type BQTN 157 [6-7]. Tujuan dari penelitian ini adalah untuk mendapatkan nilai mekanis kekuatan impak komposit serat kulit durian dengan menggunakan resin polyester [810].

\section{BAHAN DAN METODE}

Metode pengumpulan data pada penelitian ini dilakukan secara eksperimen. Yaitu melakukan serangkaian pengujian pada objek yang teliti untuk mendapatkan data yang nantinya diperlukan sebagai bahan pembahasan.

Penelitian ini dilaksanakan di Laboratorium Pengujian Material Jurusan Teknik Mesin Fakultas Teknik Universitas Pattimura dan Labolatorium Material Politeknik Ambon.

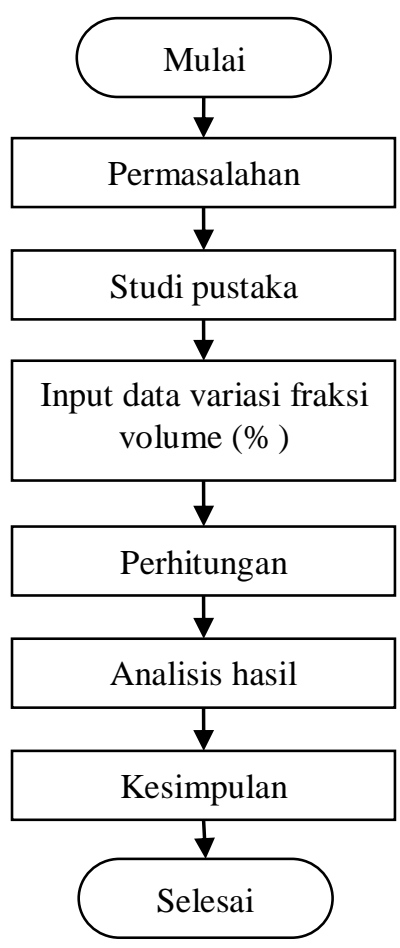

Gambar 1. Alur Penelitian 
Variabel penelitian dibedakan atas dua yakni; variabel bebas dan variabel terikat. Variabel bebas adalah variabel yang mempegaruhi, sedangkan variabel terikat adalah variabel yang di pengaruhi.

Secara matematik hubungan variabel bebas dan variabel terikat dinyatakan sebagai [11-13] :

Dimana:

$$
y=f(x)
$$

$y=$ variabel terikat adalah nilai impak $\left(\mathrm{j} / \mathrm{mm}^{2}\right)$

$\mathrm{x}=$ variabel bebas adalah fariasi fraksi volume serat kulit durian berbanding matriks polyester

Yang menjadi variasi bebas (x) adalah; variasi fraksi volume (\%)

Variabel terikat adalah Nilai impak, dimana :

$\mathrm{W}=$ energi awal - energi yang tersisa

$=\mathrm{m} \cdot \mathrm{g} \cdot \mathrm{h}-\mathrm{m} \cdot \mathrm{g} \cdot \mathrm{h}=\mathrm{m} \cdot \mathrm{g} \cdot(\mathrm{R}-\mathrm{R} \cos \alpha)$

- m.g.(R- R.cos $\beta) \mathrm{W}$

$=m g \cdot R \cdot(\cos \beta-\cos \alpha)$

Tabel 1. Variasi komposisi komposit dalam penelitian ini:

\begin{tabular}{ccc}
\hline No & Serat kulit durian & polyester \\
\hline 1 & $10 \%$ & $90 \%$ \\
2 & $20 \%$ & $80 \%$ \\
3 & $30 \%$ & $70 \%$ \\
4 & $40 \%$ & $60 \%$ \\
5 & $50 \%$ & $50 \%$ \\
\hline
\end{tabular}

Dimana :

Esrp : energi serap (J)

$\mathrm{m}:$ berat pendulum $(\mathrm{kg})$

$\mathrm{g}$ : percepatan gravitasi $\left(\mathrm{m} / \mathrm{s}^{2}\right)$

$\mathrm{R}$ : panjang lengan $(\mathrm{m})$

$\alpha$ : sudut pendulum sebelum diayunkan

$\beta$ : sudut ayunan pendulum setelah mematahkan specimen

Analisis kekuatan impak dilakukan dengan menggunakan pengujian impak Charpy. Besarnya kekuatan impak pada komposit secara makro mekanik dapat ditentukan dengan persamaan [1416]

$$
a_{C N}=\frac{W}{h \times b_{N}}
$$
lain:

Variabel terkontrol yang digunakan antara

- Penambahan MEKPO sebesar $1 \%$

- Resin poliester sebesar $50 \%$.

- Ukuran panjang serat serat durian 5-10 mm dengan arah acak

\section{HASIL DAN PEMBAHASAN}

\subsection{Hasil Pengujian Impak}

Pengujian yang dilakukan menggunakan pengujian impak charpy dengan standar ASTM E D256-00, dalam pengujian ini serat kulit durian sebagai penguat dan polyester sebagai matrik untuk fraksi volume divariasikan, hasil pengujian komposit diperoleh nilai kekuatan pengujian impak pada energi pengujian impak untuk masing-masing specimen dengan setiap perbandingan fraksi volume seperti yang terlihat pada gambar $1 \& 2$ di bawah ini :

\subsection{Pembahasan}

Dari hasil pengujian yang pengujian impak dan dapat dijelaskan sebagai berikut:

Dari hasil pengujian kekuatan Impak (Gambar 2) didapat nilai energi serap terendah pada Fraksi Volume 10\%:90\% yaitu sebesar 0,46148 J, dan seiring bertambah pada Fraksi Volume 20\%:80\% yaitu sebesar 0,6784 J, dan bertambah pada Fraksi Volume 30\%:70\% yaitu sebesar 0,6986 J, dan bertambah pada Fraksi Volume 40\%:60\% yaitu sebesar $0,7394 \mathrm{~J}$, dan tertinggi yaitu pada Fraksi Volume 50\%:50\% yaitu 0,7738 J, sedangkan untuk harga impak terendah (Gambar 3) pada fraksi volume 10\%:90\% yaitu sebesar 0,0057685 $\mathrm{J} / \mathrm{mm}^{2}$, dan terus bertambah pada fraksi volume 20\%:80\% yaitu sebesar $0,00848 \mathrm{~J} / \mathrm{mm}^{2}$, fraksi volume 30\%:70\% yaitu sebesar $0,0087325 \mathrm{~J} / \mathrm{mm}^{2}$, fraksi volume 40\%:60\% yaitu sebesar 0,0092425 $\mathrm{J} / \mathrm{mm}^{2}$, dan tertinggi yaitu pada fraksi volume 50\%:50\% yaitu sebesar 0,0096725 J/mm². Sehingga dapat disimpulkan bahwa semakin besar penambahan fraksi volume komposit serat kulit durian, maka semakin besar nilai energi serap dan harga impak.

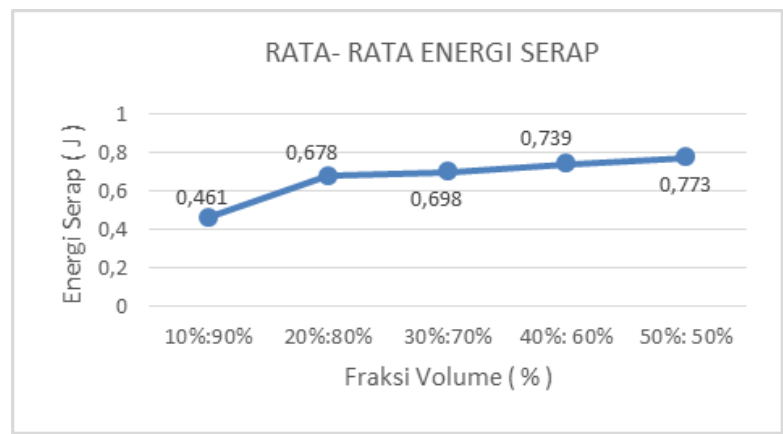

Gambar 2. Rata-rata grafik energi serap serat kulit durian 


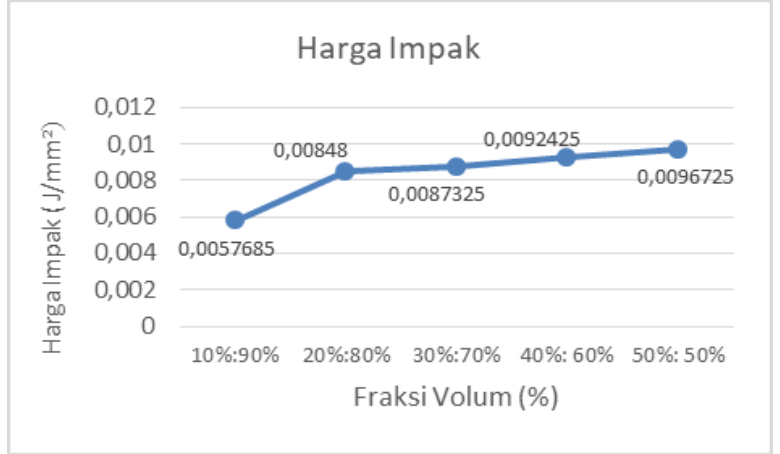

Gambar 3. Harga impak rata-rata pengujian Impak

Dari Gambar 4 dimana mengalami pola patahan yang hampir mirip dimana terlihat mekanisme fiber pull out. Dengan brittle dimana pada ujung patahan specimen juga muncul patahan serat getas.

Selain itu ada beberapa faktor pendukung meningkatnya dan kekuatan impak antara lain:
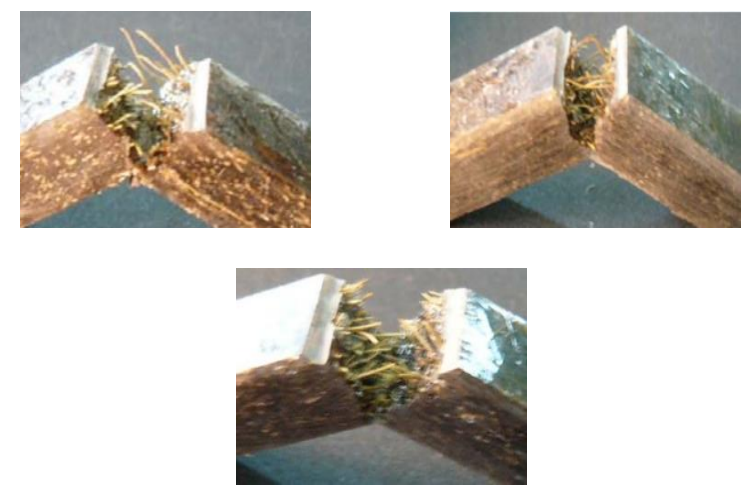

Gambar 4. Specimen Uji Impak Serat Kulit Durian

- Daya rekat antara serat dan matrik yang baik sehingga terjadi ikatan yang kuat.

- Kekuatan komposit yang merata setiap tempat sehingga terjadinya retak sampai patah hanya pada titik yang diberi konsentrasi tegangan.

- Semakin banyak jumlah volume serat maka kemungkinan untuk bergesernya serat menjadi lebih kecil ketika mendapatkan beban.

- Serat juga memiliki sifat ulet sehingga mampu menyerap beban yang diteriskan oleh matrik.

\section{KESIMPULAN}

Berdasarkan hasil pengolahan data dan pembahasan dapat disimpulkan sebagai berikut:

1. Dari hasil pengujian kekuatan Impak didapat nilai energi serap terendah pada Fraksi Volume 10\%:90\% yaitu sebesar 0,46148 J, dan seiring bertambah pada Fraksi Volume
20\%:80\% yaitu sebasar 0,6784 J, dan bertambah pada Fraksi Volume 30\%:70\% yaitu sebasar $0,6986 \mathrm{~J}$, dan bertambah pada Fraksi Volume 40\%:60\% yaitu sebasar $0,7394 \mathrm{~J}$, dan tertinggi yaitu pada Fraksi Volume 50\%:50\% yaitu 0,7738 J,

2. Sedangkan untuk harga impak terendah pada fraksi volume 10\%:90\% yaitu sebesar $0,0057685 \mathrm{~J} / \mathrm{mm}^{2}$, dan terus bertambah pada fraksi volume 20\%:80\% yaitu sebesar $0,00848 \mathrm{~J} / \mathrm{mm}^{2}$, fraksi volume $30 \%: 70 \%$ yaitu sebesar $0,0087325 \mathrm{~J} / \mathrm{mm}^{2}$, fraksi volume 40\%:60\% yaitu sebesar $0,0092425 \mathrm{~J} / \mathrm{mm}^{2}$, dan tertinggi yaitu pada fraksi volume 50\%:50\% yaitu sebesar 0,0096725 J/mm².

3. Sehingga dapat disimpulkan bahwa semakin besar penambahan fraksi volume komposit serat kulit durian, maka semakin besar nilai energi serap dan harga impak.

4. Rekomendasi, Perlu dilakukan pengembangan penelitian lebih lanjut mengenai material komposit serat kulit durian, untuk menciptakan material komposit yang baru sesuai kebutuhan produk atau sebagai pengganti material baru.

\section{UCAPAN TERIMA KASIH}

Ucapan terima kasih yang disampaikan, kepada Universitas Pattimura, yang telah membantu penelitian ini dengan menggunakan dana PNBP Unpatti tahun 2020.

\section{DAFTAR PUSTAKA}

[1] Diharjo K., 2009 Pengaruh Perlakuan Alkali terhadap sifat Tarik Bahan Komposit Serat Rami-Polyester. Jurusan Teknik Mesin, Fakultas Teknologi Industri, Universitas Kristen Petra.

[2] Pramuko 1 Purboputro, 2006, Pengaruh Panjang Serat Terhadap Kekuatan Impak Enceng Gondok dengan Matrikk Polyester MEDIA MESIN, Vol. 7, No. 2, 70- 76

[3] Wahyono, 2009, Karakteristik Edible Film Berbahan Dasar Kulit Durian dan Pati Biji Durian (Durio sp) untuk Pengemasan Buah Strawberry. Skripsi. UMS.

[4] Indra Syahrul Fuad, Bahder Djohan, Midun Saputra (2014), meneliti tentang "Pengaruh penambahan serat kulit durian terhadap kuat tekan dan tarik belah pada mutu beton K175".Jurnal Desiminasi Teknologi, Vol.2 No.1.

[5] Diharjo K, 2006, Pengaruh Perlakuan Alkali terhadap Sifat Tarik Bahan Komposit Serat Rami - Polyester, Jurnal Teknik Mesin Vol. 8, No. 1, Petra Christian University, Jakarta. 
[6] H.P.G. Santafe Junior, et.al., 2010 Mechanical Properties of Tensile Tested Coir Fiber Reinforced Polyester Composites. Revista Material.

[7] Majid Ali., 2010. Coconut Fiber - A Versatile Material and is Applications inEngineering, National Engineering

[8] Flach M., 1983. The Sago Palm. FAO Plant Production and Protection, Paper. FAORome:85p.

[9] Jacobs, J.A. Kilduft T.K. 1994. Engineering Material Technology Structure, Processing, Property and Selection 2. Prentice Hall,Inc A Simon Schuster Company, USA.

[10] ASTM. 1997. Mannual book of ASTM standarts. Philadelphia : ASTM

[11] ASTM,. 1998. Annual Book ASTM Standar USA.
[12] ASTM D256-00 ISO 179-1., 2003, Standart Test Method for Tensile Properties of plastic, 47-60

[13] ASTM. D 790 Standard test methods for flexural properties of unreinforced and reinforced plastics and electrical insulating material. Philadelphia, PA : American Society for Testing and Materials.

[14] Budinski Keneth G., 2003. Engineering Material Properties and Selection, Prentice Hall, New Jesey

[15] Callister, W. D. 1991. Material Science and Engineering an Introduction, John Willey and Sons Inc, New York.

[16] Bismarck, A. et al. 2002. Surface Characterization of Flax, Hemp and Cellulose Fiber; Surface Properties anda the Water Uptake Behavior. Journal of Polymer Composite. Vol.23. No.5. 